\title{
Estudo do efeito dos parâmetros do tratamento da limpeza a plasma na adesão e resistência ao desgaste de filmes DLC em liga de $\mathrm{Ti}_{6} \mathrm{Al}_{4} \mathrm{~V}$
}

Study of the effect of plasma cleaning treatment parameters on adhesion and wear resistance of $\mathrm{Ti}_{6} \mathrm{Al}_{4} \mathrm{~V}$ DLC films

Larissa Solano de Almeida1*, Alan Roger Moreno de Souza1, Marcos Dorigão Manfrinato1,2, Luciana Sgarbi Rossino ${ }^{1,2}$

\section{RESUMO}

Tratamentos a plasma vêm sendo amplamente utilizados com o objetivo de melhorar as características em desgaste, corrosão e fadiga dos materiais metálicos. Porém, para produção da camada ou adesão de revestimento, a etapa de limpeza a plasma deve ser efetiva. O objetivo deste trabalho é demonstrar o efeito dos parâmetros do processo de ablação a plasma na limpeza da superfície e adesão de filmes diamond-like carbon (DLC) em liga $\mathrm{Ti}_{6} \mathrm{Al}_{4} \mathrm{~V}$. As superfícies foram limpas pelo processo de ablação a plasma utilizando fonte DC-pulsada, variando a pressão de trabalho (0,39 a 2,00 Torr), tipo ( $\mathrm{Ar}$ e $\mathrm{H}_{2}$ ) e proporção (100 a 50\% de $\mathrm{Ar}$ e 0 a $50 \%$ de $\mathrm{H}_{2}$ ) dos gases. Avaliou-se a adesão e a resistência ao desgaste do filme DLC depositado na superfície da liga $\mathrm{Ti}_{6} \mathrm{Al}_{4} \mathrm{~V}$ após cada etapa do processo de ablação estudado. Observou-se redução dos óxidos presentes na superfície da liga em pressões maiores de tratamento utilizando mistura gasosa $\left(\mathrm{Ar}\right.$ e $\mathrm{H}_{2}$ ), evidenciando que esses parâmetros são fatores determinantes para se obter menor volume de desgaste e maior adesão do filme DLC na superfície tratada.

Palavras-chave: Argônio, Hidrogênio, Ablação, Carbono tipo diamante, DC-PECVD.

\section{ABSTRACT}

Plasma treatments have been widely used to improve the wear, corrosion and fatigue characteristics of metallic materials. However, the plasma cleaning stage must be effective for production of the layer or coating adhesion. The objective of this work is to demonstrate the effect of parameters of the plasma ablation process in surface cleaning and adhesion of diamond-like carbon (DLC) films in $\mathrm{Ti}_{6} \mathrm{Al}_{4} \mathrm{~V}$ alloy. The surfaces were cleaned by the plasma ablation process using pulsed DC source, varying the pressure of work ( 0.39 to 2.00 Torr), type $\left(\mathrm{Ar}\right.$ and $\mathrm{H}_{2}$ ) and proportion (100 to $50 \%$ of $\mathrm{Ar}$ and 0 to $50 \%$ of $\mathrm{H}_{2}$ ) of the gases. The adhesion and wear resistance of the DLC film deposited on the surface of the $\mathrm{Ti}_{6} \mathrm{Al}_{4} \mathrm{~V}$ alloy was evaluated after each stage of the studied ablation process. A reduction in the oxides present on the surface of the alloy was observed at higher treatment pressures using a gas mixture $\left(\right.$ Ar and $\left.\mathrm{H}_{2}\right)$, which showed that these parameters are determining factors in obtaining low wear volume and greater adhesion of the DLC film on the treated surface.

Keywords:Argon, Hydrogen, Ablation, Diamond-like carbon, DC-PECVD.

1.Universidade Federal de São Carlos - Centro de Ciências e Tecnologias para a Sustentabilidade - Programa de Pós-graduação em Ciência dos Materiais Sorocaba (SP), Brasil.

2.Faculdade de Tecnologia José Crespo Gonzales - Centro Paula Souza - Laboratório de Tecnologia e Engenharia de Superfície - Sorocaba (SP), Brasil.

*Autora correspondente: solano.larissa@gmail.com

Recebido: 19 Mar 2020 Aceito: 6 Abr 2020 


\section{INTRODUÇÃO}

Tratamentos a plasma são cada vez mais empregados para modificações da superfície de materiais a fim de aprimorá-las para determinadas aplicações. O tratamento a plasma realizado em plásticos, por exemplo, pode causar a formação de radicais químicos na superfície, tornando-a ativa para melhorar a adesão de revestimentos ou melhorar sua molhabilidade ${ }^{1}$. Já em cerâmica, a modificação da superfície visa geralmente melhorar o processo de adesão entre materiais de naturezas diferentes ${ }^{2}$. Nos metais, o tratamento a plasma pode ser realizado para alterar química e estruturalmente a superfície do material (tratamento termoquímico), para a deposição de revestimento ou filmes finos ou para a realização do processo de ablação a plasma, que pode ser utilizada para a limpeza da superfície (etching ou sputtering) ${ }^{3}$. Além disso, os tratamentos a plasma podem ser utilizados em meio ambiente e em materiais avançados, envolvendo uma vasta gama de aplicações e metodologias, correspondendo a uma tecnologia limpa, barata e econômica ${ }^{4}$.

Os filmes carbono tipo diamante ou diamond-like carbon (DLC) têm despertado o interesse dos pesquisadores para aplicações industriais devido às suas propriedades notáveis, como baixo coeficiente de atrito, alta dureza, inércia química e resistência à corrosão, além de serem biocompatíveis. Esses filmes têm sido aplicados em discos rígidos magnéticos, lâminas, implantes, próteses médicas, componentes aeronáuticos, entre outros ${ }^{5-7}$.

O filme DLC corresponde à formação de uma estrutura amorfa de carbono com a presença de ligação entre carbono do tipo sp ${ }^{2} \mathrm{e}$ $\mathrm{sp}^{3}$ em proporções distintas que, juntamente com a quantidade de hidrogênio, determina o tipo e as propriedades do filme produzido ${ }^{8}$.

Porém, como reportado por Petry ${ }^{9}$, a grande diferença entre o coeficiente elástico e a dilatação térmica entre o filme DLC e o substrato metálico dificulta o processo de adesão entre eles. Dessa maneira, a utilização de técnicas mais efetivas de limpeza a plasma da superfície para remoção da camada de óxido através do bombardeamento iônico (ablação), a alteração da morfologia superficial do substrato, o uso de intercamadas de filmes precedentes ao filme DLC, a dopagem do filme com diferentes elementos e o resfriamento gradual do material após a finalização do tratamento podem melhorar a característica de baixa adesão dos filmes DLC em substratos metálicos ${ }^{10,11}$.

A técnica de ablação, utilizada para remoção de óxidos e uniformização das superfícies, proporciona melhora na adesão de revestimentos ao substrato, influencia na biocompatibilidade do material e rugosidade da superfície ${ }^{12-14}$.

A ablação utiliza, geralmente, um plasma de argônio para bombardeamento da superfície do substrato, promovendo assim a remoção dos óxidos e a alteração morfológica superficial, resultando em um filme de DLC mais uniforme e aderente. Jones et al. ${ }^{15}$ estudaram o processo de sputtering na alteração da morfologia superficial utilizando a técnica de limpeza por plasma de argônio. Como resultado, observaram que a maior tensão aplicada ao sistema promove superfícies mais uniformes, promovendo assim filmes mais aderentes e com menores rugosidades.

Este trabalho tem como objetivo investigar a influência dos parâmetros do processo de ablação a plasma, como pressão de trabalho, tipo e proporção dos gases na limpeza da superfície da liga $\mathrm{Ti}_{6} \mathrm{Al}_{4} \mathrm{~V}$ e verificar se esses parâmetros têm influência direta na propriedade de adesão e resistência ao desgaste do filme DLC depositado na superfície da liga estudada.

\section{MATERIAIS E MÉTODOS}

Para o desenvolvimento deste trabalho, utilizou-se a liga $\mathrm{Ti}_{6} \mathrm{Al}_{4} \mathrm{~V}$ na dimensão de $14 \times 14 \times 9 \mathrm{~mm}$, como mostra a Fig. 1 . As amostras polidas passaram por um processo de limpeza prévia para a realização do tratamento a plasma, realizada em água deionizada com detergente e posteriormente em álcool isopropílico, deixadas em cuba ultrassônica de limpeza (Yaxun 3560), com 50 W de potência e por um período de 5 min em cada etapa, secas utilizando soprador térmico.

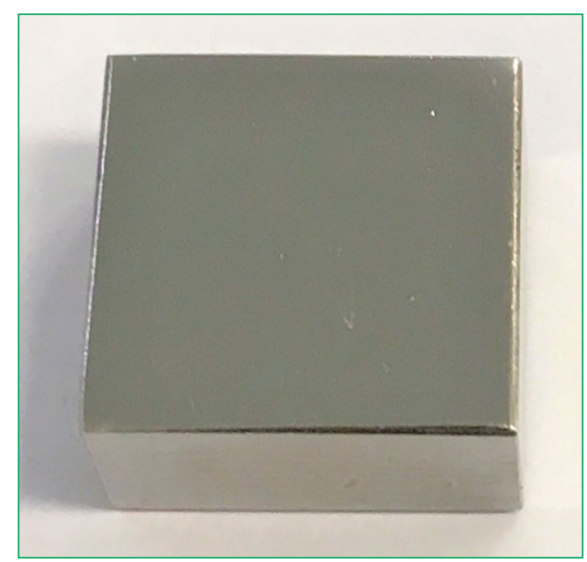

Figura 1: Amostra sem tratamento. 
Os tratamentos foram realizados no Laboratório de Tecnologia e Engenharia de Superfícies (LabTES) da Faculdade de Tecnologia José Crespo Gonzales (Fatec) de Sorocaba. Utilizou-se um sistema cujo esquema utilizado está apresentado na Fig. 2, com bomba mecânica, sensor Pirani para medir a pressão, fonte DC-pulsada, um termopar do tipo K inserido em uma amostra posicionada no eletrodo inferior de tratamento (cátodo) para medir a temperatura do processo e um sistema de inserção de gases com fluxômetros digitais e válvula-agulha. O detalhamento do sistema é apresentado em Cruz et al. ${ }^{3}$.

Após limpas, as amostras foram posicionadas no eletrodo inferior do reator e fez-se vácuo no sistema. Ao atingir a pressão de fundo de $3 \times 10^{-2}$ Torr (4 Pa), iniciou-se o processo de limpeza por ablação a plasma.

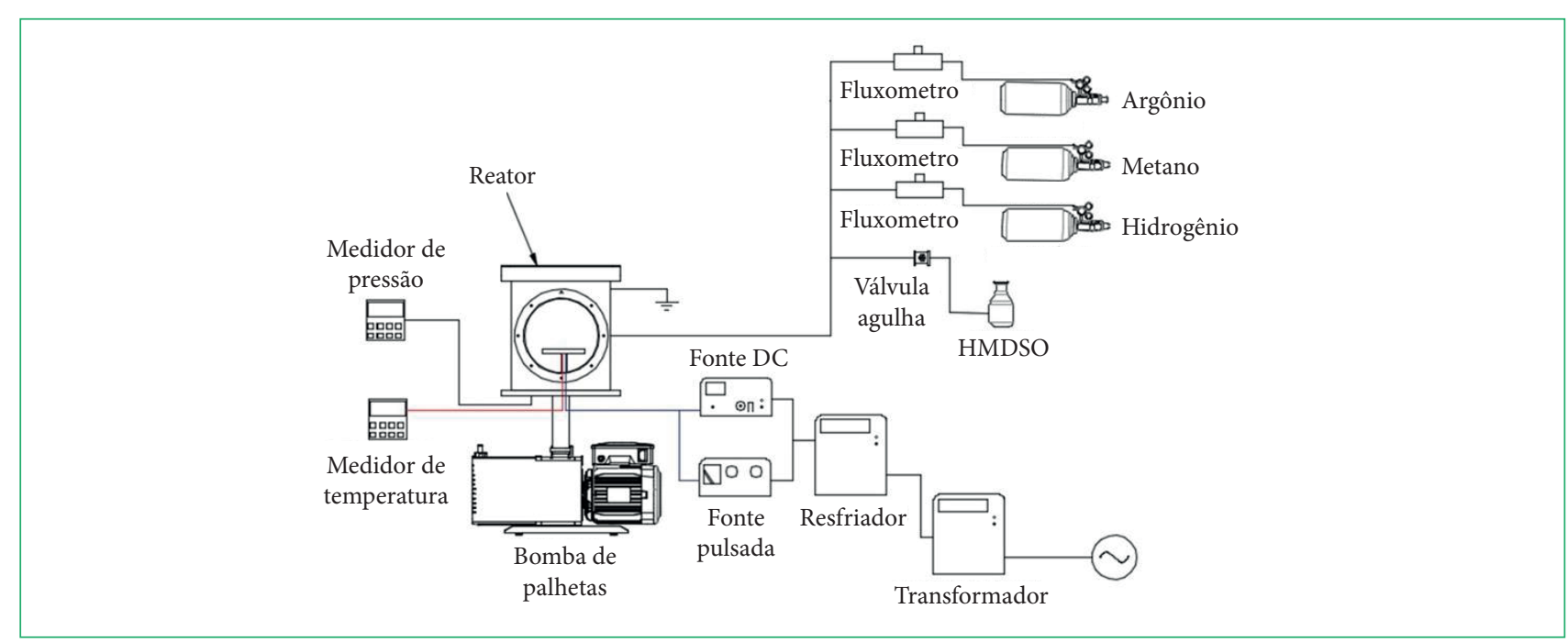

Figura 2: Esquema do sistema de tratamento a plasma.

As etapas de tratamento a plasma envolveram a limpeza a plasma da superfície (ablação), a deposição de uma intercamada de silício amorfo utilizando hexametildisiloxano (HMDSO) como precursor e a deposição do filme DLC.

Para estudo do efeito dos parâmetros da limpeza a plasma nas modificações superficiais da liga estudada, a etapa de ablação a plasma foi realizada por 30 min utilizando-se gás argônio e hidrogênio. Variaram-se a pressão total dos gases e a proporção de argônio e hidrogênio. A Tabela 1 apresenta os parâmetros utilizados para o tratamento de ablação. As amostras foram avaliadas após essa etapa, sem deposição do filme DLC, analisando o aspecto visual do plasma, o aspecto visual das amostras e a análise das modificações superficiais das amostras por espectroscopia por energia dispersiva (EDS - energy dispersive spectroscopy) via microscopia eletrônica de varredura (MEV), espectroscopia de infravermelho com transformada de Fourier (FTIR) e difração de raios-X (DRX).

Para o estudo do comportamento da adesão e resistência ao desgaste do filme DLC na superfície metálica estudada, os tratamentos foram realizados por deposição química a vapor assistida por plasma (PECVD - plasma-enhanced chemical vapor deposition) utilizando fonte DC-pulsada seguindo os parâmetros apresentados na Tabela 2.

Tabela 1: Parâmetros para ablação a plasma dos substratos de liga de $\mathrm{Ti}_{6} \mathrm{Al}_{4} \mathrm{~V}$.

\begin{tabular}{|c|c|c|c|c|c|}
\hline Amostras & Proporção de gases & $\begin{array}{c}\text { Pressão de trabalho } \\
\text { (Torr) }\end{array}$ & $\begin{array}{l}\text { Tensão } \\
\text { (V) }\end{array}$ & $\begin{array}{l}\text { Tempo } \\
\text { (min) }\end{array}$ & $\begin{array}{c}\text { Temperatura } \\
\left({ }^{\circ} \mathrm{C}\right)\end{array}$ \\
\hline$A B L 100 \mathrm{Ar}-0.39$ & $100 \% \mathrm{Ar}$ & 0,39 & 470 & \multirow{8}{*}{30} & \multirow{8}{*}{ \pm 300} \\
\hline$A B L 100 \mathrm{Ar}-1.00$ & $100 \% \mathrm{Ar}$ & 1,00 & 378 & & \\
\hline$A B L 100 \mathrm{Ar}-1.80$ & $100 \% \mathrm{Ar}$ & 1,80 & 311 & & \\
\hline $\mathrm{ABL} 80 \mathrm{Ar}-0.39$ & $80 \% \operatorname{Ar} 20 \% \mathrm{H}_{2}$ & 0,39 & 411 & & \\
\hline ABL80Ar -1.00 & $80 \% \operatorname{Ar} 20 \% \mathrm{H}_{2}$ & 1,00 & 381 & & \\
\hline $\mathrm{ABL} 80 \mathrm{Ar}-1.80$ & $80 \% \operatorname{Ar} 20 \% \mathrm{H}_{2}$ & 1,80 & 311 & & \\
\hline $\mathrm{ABL} 80 \mathrm{Ar}-2.00$ & $80 \% \operatorname{Ar} 20 \% \mathrm{H}_{2}$ & 2,00 & 321 & & \\
\hline $\mathrm{ABL} 50 \mathrm{Ar}-2.00$ & $50 \% \operatorname{Ar} 50 \% \mathrm{H}_{2}$ & 2,00 & 315 & & \\
\hline
\end{tabular}


Tabela 2: Parâmetros para ablação a plasma, deposição da interface de silício e do filme DLC na liga $\operatorname{Ti}_{6} \mathrm{Al}_{4} \mathrm{~V}$.

\begin{tabular}{|c|c|c|c|c|c|c|}
\hline \multirow{2}{*}{ Amostras } & \multicolumn{3}{|c|}{ Interface de silício } & \multicolumn{3}{|c|}{ Filme DLC } \\
\hline & Gases (\%) & Tensão (V) & Tempo (min) & Gases (\%) & Tensão (V) & Tempo (h) \\
\hline DLC-ABL100Ar - 0.39 & \multirow{7}{*}{$70 \mathrm{HMDSO}-30 \mathrm{Ar}$} & \multirow{7}{*}{500} & \multirow{7}{*}{15} & \multirow{7}{*}{$90 \mathrm{CH}_{4}-10 \mathrm{Ar}$} & \multirow{7}{*}{500} & \multirow{7}{*}{2} \\
\hline DLC-ABL100Ar - 1.00 & & & & & & \\
\hline DLC-ABL100Ar - 1.80 & & & & & & \\
\hline DLC-ABL80Ar - 0.39 & & & & & & \\
\hline DLC-ABL80Ar - 1.00 & & & & & & \\
\hline DLC-ABL80Ar - 1.80 & & & & & & \\
\hline DLC-ABL50Ar -2.00 & & & & & & \\
\hline
\end{tabular}

Assim, imediatamente após a etapa de ablação a plasma, uma interface de silício amorfo foi depositada sobre a superfície da amostra, utilizando como precursor o HMDSO e o argônio, a uma temperatura de tratamento de aproximadamente $200{ }^{\circ} \mathrm{C}$ e

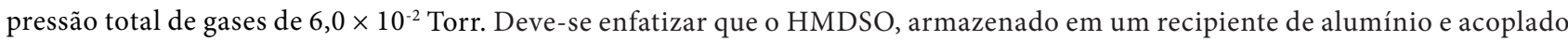
a uma das entradas do reator de tratamento a plasma, foi introduzido ao reator separadamente do argônio, sem utilização de sistema de evaporação, utilizando uma válvula-agulha. O HMDSO, por ser um líquido altamente volátil, é introduzido ao reator por diferença de pressão, onde ioniza-se juntamente com o argônio para formar o filme de silício na superfície da amostra.

Posteriormente à deposição do filme de silício, os filmes DLC foram depositados utilizando-se metano $\left(\mathrm{CH}_{4}\right)$ como principal precursor, com uma pressão total de gases de $3,0 \times 10^{-1}$ Torr e temperatura de $116^{\circ} \mathrm{C}$. Após os tratamentos, as amostras foram analisadas utilizando-se a técnica de análise visual para verificar ocorrência, tipo e processo da delaminação do filme produzido, ensaio de dureza Rockwell C para determinar a adesão do filme ao substrato e ensaio de microdesgaste abrasivo por esfera fixa.

A avaliação visual foi feita imediatamente após a retirada das amostras do reator. Para as amostras que passaram somente pelo processo de ablação, verificou-se a uniformidade e a coloração da superfície. Para as amostras com deposição de filme DLC, analisaram-se a coloração, a uniformidade e possíveis pontos de delaminação nos filmes obtidos. Análises visuais da luminescência do plasma também foram realizadas. Para tanto, as imagens foram obtidas utilizando-se câmera fotográfica com 16 megapixels.

Os tipos de óxido formados na superfície da amostra após ablação foram definidos pela análise de FTIR, realizadas nas amostras metálicas no Laboratório de Plasmas Tecnológicos (LaPTec) do Câmpus Experimental de Sorocaba da Universidade Estadual Paulista Júlio de Mesquita Filho (Unesp), utilizando um espectrômetro JASKO modelo FTIR-410. O tempo de varredura utilizado foi de $128 \mathrm{~s}$ e a resolução de $4 \mathrm{~cm}^{-1}$.

Com a técnica de EDS via MEV, foi possível fazer uma análise elementar semiquantitativa do oxigênio presente na superfície da amostra após o processo de ablação. Para tanto, foi utilizado o equipamento de bancada (Hitachi, modelo TM 3000) existente no Laboratório de Pesquisa de Bioenergia e Materiais Lignocelulósicos da UFSCar no Campus Sorocaba. O equipamento foi previamente calibrado com fita de cobre. O feixe de elétrons emitidos foi de $15 \mathrm{kV}$ utilizando sinal de elétron retroespalhado.

A análise de difração de raios-X foi realizada a fim de caracterizar os tipos de óxido existentes na superfície do metal após o processo de ablação. As análises de DRX foram realizadas na UFSCar - Campus Sorocaba, utilizando-se um equipamento marca Shimadzu XRD 6100. O tempo de análise foi de 30 min para cada amostra, em modo step scan com tensão e corrente respectivas de $40 \mathrm{kV}$ e $30 \mathrm{~mA}$, ângulo de incidência rasante, com radiação monocromática $\mathrm{Cu} \mathrm{k} \alpha$.

O teste de dureza Rockwell C foi realizado para determinar a adesão do filme DLC ao substrato após ser submetido a diferentes parâmetros de tratamento de ablação a plasma. O dano formado no filme após o ensaio de dureza foi comparado com o padrão apresentado na Fig. 3, sendo então classificado como aprovado ou reprovado ${ }^{16}$. Os ensaios foram realizados no Laboratório de Tratamento Térmico da Fatec de Sorocaba e as indentações produzidas foram analisadas utilizando um MEV de bancada (Hitachi, modelo TM 3000) existente no Laboratório de Pesquisa de Bioenergia e Materiais Lignocelulósicos, da UFSCar no Campus Sorocaba. Análises quantitativas da área delaminada foram realizadas pelo programa ImageJ, comparando a área total analisada com a região delaminada, conforme descrito por Capote et al. ${ }^{17}$.

O ensaio de microdesgaste abrasivo pode ser utilizado para a avaliação das propriedades tribológicas de um material, com um dos objetivos de determinar a resistência ao desgaste do material, permitindo, assim, a avaliação da durabilidade de componentes mecânicos. Na área de filmes finos, o ensaio de microdesgaste abrasivo também pode avaliar, juntamente com a resistência, a adesão de filmes ao substrato. Essa técnica consiste em promover o desgaste de um corpo de prova (amostra) pelo seu contato com uma esfera de raio R e partículas abrasivas. 


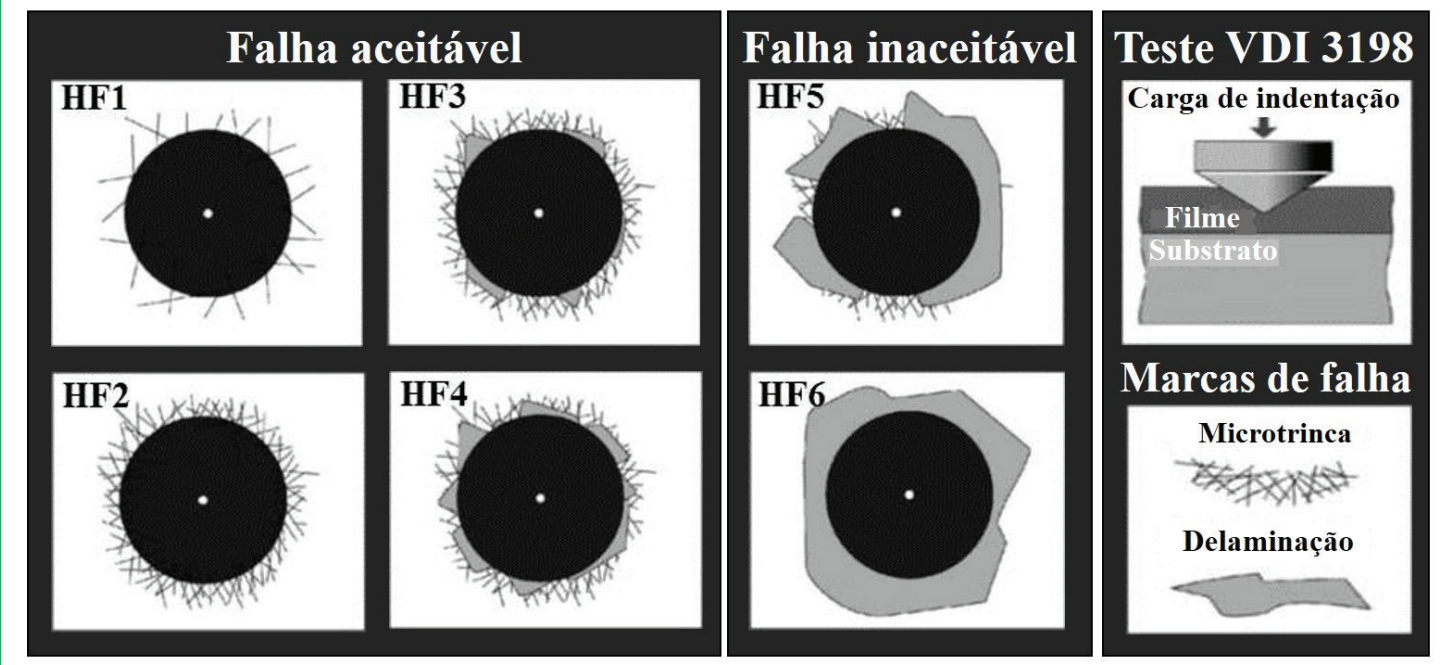

Figura 3: Padrão de dano superficial produzido em filmes através de ensaio de dureza Rockwell $\mathrm{C}^{16}$.

Para o desenvolvimento deste trabalho, utilizou-se o ensaio de microdesgaste abrasivo de esfera fixa. Nesse ensaio, aplica-se determinada carga, que é sobreposta à esfera e ao corpo de prova localizado perpendicularmente à esfera e pode ser alterada de acordo com o ensaio. Conhecendo as dimensões da calota gerada no ensaio de microdesgaste abrasivo, pode-se obter o volume de desgaste $(V)$ (Eq. 1), que determina a resistência ao desgaste do material, em que $d$ corresponde ao diâmetro da calota produzida ${ }^{18}$.

$$
V=\frac{\pi x d^{4}}{64 x R}
$$

Os ensaios de microdesgaste abrasivo foram realizados no LabTES, com carga de ensaio de $8 \mathrm{~N} \mathrm{a} 40 \mathrm{~Hz}$ (160 rpm) de rotação e tempo de 10 min. Foram realizados pelo menos dois ensaios por amostra sem lubrificante ou adição de abrasivos.

\section{RESULTADOS E DISCUSSÃO}

\section{Avaliação do processo de ablação a plasma}

As luminescências do plasma e a análise visual superficial das amostras para cada parâmetro utilizado no processo de ablação a plasma, sem deposição do filme DLC, são apresentadas na Tabela 3. Como pode ser observado, o aumento da pressão de trabalho causa uma aproximação da região catódica do plasma nas amostras, reduzindo a espessura da região mais brilhante, além de tornála mais fina, uniforme e concentrada sobre o cátodo.

Cruz et al. $^{3}$ observaram que a luminosidade no plasma está relacionada a diferentes fatores, como a alteração de pressão e potência. Os resultados aqui apresentados corroboram os resultados apresentados por Cruz et al. ${ }^{3}$, e enfatizam que a pressão tem relação direta com o comportamento da luminescência, influenciando a coloração da superfície da amostra após o processo de ablação a plasma.

A pressão dos gases nos tratamentos tem influência sobre o bombardeamento iônico. A densidade iônica pode ser relacionada à geometria do plasma. Uma luminescência mais intensa e com o contorno mais definido (bainha) indica maiores densidades iônicas. Estudos descrevem que a região da bainha apresenta menor definição em pressões mais baixas, e a luminescência apresenta um gradiente em sua região escura, caracterizando um tratamento não uniforme. As amostras que são tratadas nessas pressões apresentam a região central tratada e as extremidades sem tratamento algum. Entretanto, para altas pressões de tratamento, as amostras apresentam comportamento contrário, em que a região da bainha é mais definida nas extremidades e apresentam menor definição no centro, também caracterizadas por regiões sem nenhum tratamento ou com pouca camada formada. Portanto, tanto para o processo de ablação a plasma quanto para as etapas de tratamento de superfície, deve-se encontrar um valor de pressão intermediário ideal, para se obter uma alta densidade de íons em toda a superfície da amostra. Assim, para o processo de ablação a plasma, deve-se obter maior incidência de bombardeamentos de alta energia em toda a extensão da superfície da amostra a fim de obter maiores interações atômicas entre o plasma e a superfície tratada, resultando na remoção das contaminações e oxidações superficiais das amostras $3,19,20$. 
Tabela 3: Análise visual da luminescência e superfície das amostras após ablação a plasma, sem deposição de filme DLC.

\begin{tabular}{|c|c|c|}
\hline Amostras & Luminescência & Análise Visual da Amostra \\
\hline$A B L 100 A r-0.39$ & 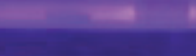 & \\
\hline$A B L 100 \mathrm{Ar}-1.00$ & & \\
\hline ABL100Ar -1.80 & & \\
\hline$A B L 80 A r-0.39$ & & \\
\hline $\mathrm{ABL} 80 \mathrm{Ar}-1.00$ & & \\
\hline $\mathrm{ABL} 80 \mathrm{Ar}-1.80$ & & \\
\hline$A B L 80 A r-2.00$ & & \\
\hline ABL50Ar -2.00 & & \\
\hline
\end{tabular}

Conforme verificado na Tabela 3, pressões baixas causam uma forte coloração na superfície da amostra tratada, mais intensa no centro, com a formação de efeito de borda com geometria semelhante ao seu formato, como observado na amostra ABL100Ar-0.39. A amostra ABL100Ar-1.00 apresentou coloração amarela no centro, com efeito de borda.

Já as amostras tratadas nas pressões mais altas, cuja luminescência do plasma está uniforme e fina, o aspecto visual superficial depende do tipo e da proporção do gás utilizado no tratamento. A amostra ABL100Ar-1.80, tratada somente com gás argônio, apresentou coloração amarela intensa e uniforme por toda a superfície. As amostras tratadas com mistura de argônio e hidrogênio (ABL80Ar-0.39 
e ABL80Ar-1.00) apresentaram coloração amarela mais clara, e a amostra ABL80Ar-1.80 apresentou coloração metálica, semelhante àquela observada na amostra sem tratamento.

Assim, tendo sido mantidas constantes a pressão e a temperatura de tratamento, sendo alterada apenas a proporção de gases, observa-se que não só a pressão, mas também o tipo e a proporção dos gases utilizados para a realização da limpeza são fatores que contribuem para a remoção de impurezas da superfície das amostras.

Silva et al. ${ }^{13}$, ao utilizarem argônio e hidrogênio no processo de limpeza na liga $\mathrm{Ti}_{6} \mathrm{Al}_{4} \mathrm{~V}$, observaram que a rugosidade e a energia de superfície aumentam. Utilizando a proporção de gases de 50\% de $\mathrm{Ar}$ e 50\% de $\mathrm{H}_{2}$ durante $30 \mathrm{~min}$, obteve-se melhor biocompatibilidade para o material tratado, com diferença de aproximadamente $90 \%$ de melhora em relação à amostra sem tratamento.

Siqueira ${ }^{21}$ observou que a limpeza influencia diretamente na espessura do filme formado, sendo que ao se utilizar argônio e hidrogênio na proporção de 80 a $20 \%$, houve a formação de uma camada mais espessa formada na superfície da liga $\mathrm{Ti}_{6} \mathrm{Al}_{4} \mathrm{~V}$ oxidada a plasma. $\mathrm{O}$ material oxidado que utilizou a proporção de gases na etapa de ablação a plasma de $80 \%$ Ar e $20 \% \mathrm{H}_{2}$ obteve maior resistência ao desgaste comparado ao material oxidado sob as mesmas condições e utilizando a proporção de gases de $50 \%$ de $\mathrm{Ar}$ e $50 \%$ de $\mathrm{H}_{2}$ no processo de ablação a plasma.

Assim, esses resultados indicam que a pressão de trabalho no processo de limpeza é importante para evitar efeito de borda na amostra, fato constatado por Cruz et al. ${ }^{3}$, e que a presença do $\mathrm{H}_{2}$ nessa etapa é crucial para a retirada dos óxidos superficiais ${ }^{13}$.

$\mathrm{Na}$ Fig. 4 são apresentados os espectros obtidos por FTIR da superfície da liga $\mathrm{Ti}_{6} \mathrm{Al}_{4} \mathrm{~V}$ preparada, polida e limpa quimicamente, sem tratamento a plasma. O espectro apresenta bandas de absorção na região das ligações de compostos orgânicos. $\mathrm{Na}$ região de $1450 \cdot \mathrm{cm}^{-1}$, observam-se as ligações de $\mathrm{CH}_{3}$ (alcanos) com modo de dobramento. Observam-se as ligações $\mathrm{C}=\mathrm{C}$ (alcenos) na região de $1680 \cdot \mathrm{cm}^{-1}$, e as ligações $\mathrm{C} \equiv \mathrm{C}$ (alcinos) na região de $2100 \cdot \mathrm{cm}^{-1}$. Observam-se também as ligações de carbono entre 900 a $690 \cdot \mathrm{cm}^{-1}$ indicando a presença de aromáticos, com modo de dobramento fora do plano, e bandas próximas de $400 \cdot \mathrm{cm}^{-1}$, referentes à ligação Ti- $\mathrm{O}^{22,23}$. Portanto, mesmo com a limpeza química da superfície após a preparação e o polimento da amostra, não se eliminam totalmente as impurezas orgânicas e inorgânicas, apresentando resíduos na superfície.

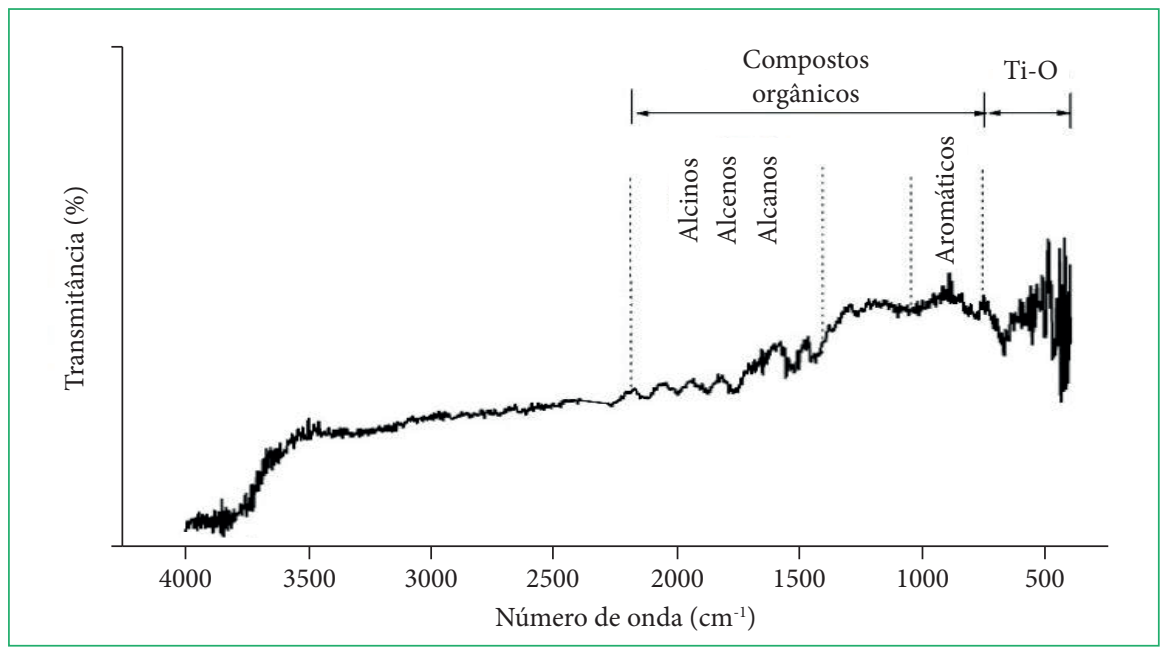

Figura 4: Espectros obtidos pela técnica de FTIR da superfície do substrato preparado e limpo quimicamente, sem tratamento a plasma.

Na Fig. 5 são apresentados os espectros obtidos por FTIR das amostras limpas por ablação a plasma com 100\% de argônio no processo, alterando a pressão de trabalho. Os espectros para diferentes pressões de trabalho apresentaram semelhanças nos picos obtidos, porém é verificada a diminuição da absorção das bandas próximas de 400 a $680 \cdot \mathrm{cm}^{-1}$, referentes à ligação Ti-O ${ }^{22,23}$, confirmando a remoção dos óxidos da superfície no processo de ablação a plasma para pressão de trabalho maior.

A redução das bandas de absorção da ligação Ti-O em maior pressão de tratamento também é observada com a adição de hidrogênio nos processos de ablação a plasma, como pode ser observado na Fig. 6.

Observa-se que a adição de hidrogênio no processo de limpeza influencia positivamente na remoção de óxidos da superfície. Ao comparar os espectros das superfícies tratadas somente com argônio com os espectros das superfícies das amostras tratadas com argônio e hidrogênio, verifica-se que a limpeza por ablação a plasma promove uma redução das bandas na região de absorção da ligação de Ti-O, entre 400 a $680 \cdot \mathrm{cm}^{-1}$ para as condições de maior pressão de trabalho com a presença do hidrogênio ${ }^{22,23}$. Nota-se também que não são apresentadas as bandas significativas na região de absorção das ligações de compostos orgânicos de C-H, em torno de 1400 a $2100 \cdot \mathrm{cm}^{-1}$, em nenhum dos espectros referentes às amostras limpas pelo processo de ablação a plasma, evidenciado a efetiva remoção de compostos orgânicos e inorgânicos residuais ${ }^{22,23}$. Como descrito por Petasch et al.24, os compostos orgânicos provenientes de impurezas 
residuais presentes na superfície da amostra são volatilizados durante o processo a plasma, sendo eliminados da atmosfera de tratamento, efetivando a limpeza da amostra, o que corrobora os resultados obtidos neste trabalho.

Os difratogramas obtidos por difração de raios-X para as amostras tratadas somente com argônio são apresentados na Fig. 7. Foram identificados os picos referentes à fase alfa ( $\alpha$ - hexagonal compacta) do substrato de titânio, presentes nos ângulos $35^{\circ}, 40^{\circ}, 55^{\circ}$ e $65^{\circ}$, e

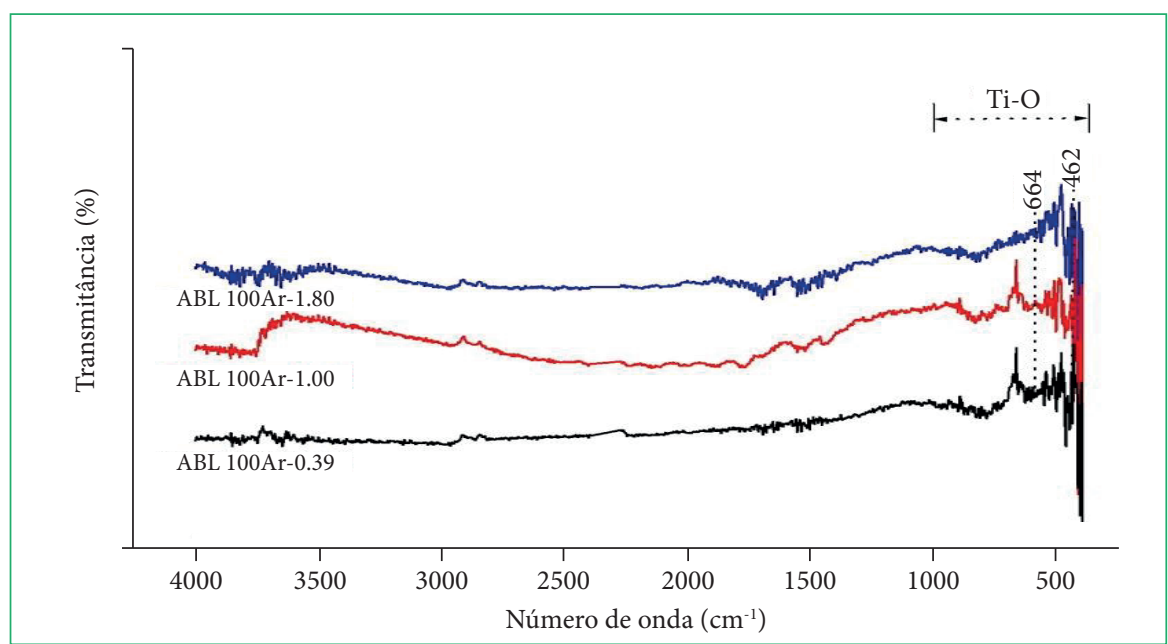

Figura 5: Espectros obtidos pela técnica de FTIR das superfícies com 100\% de argônio no processo de ablação a plasma.

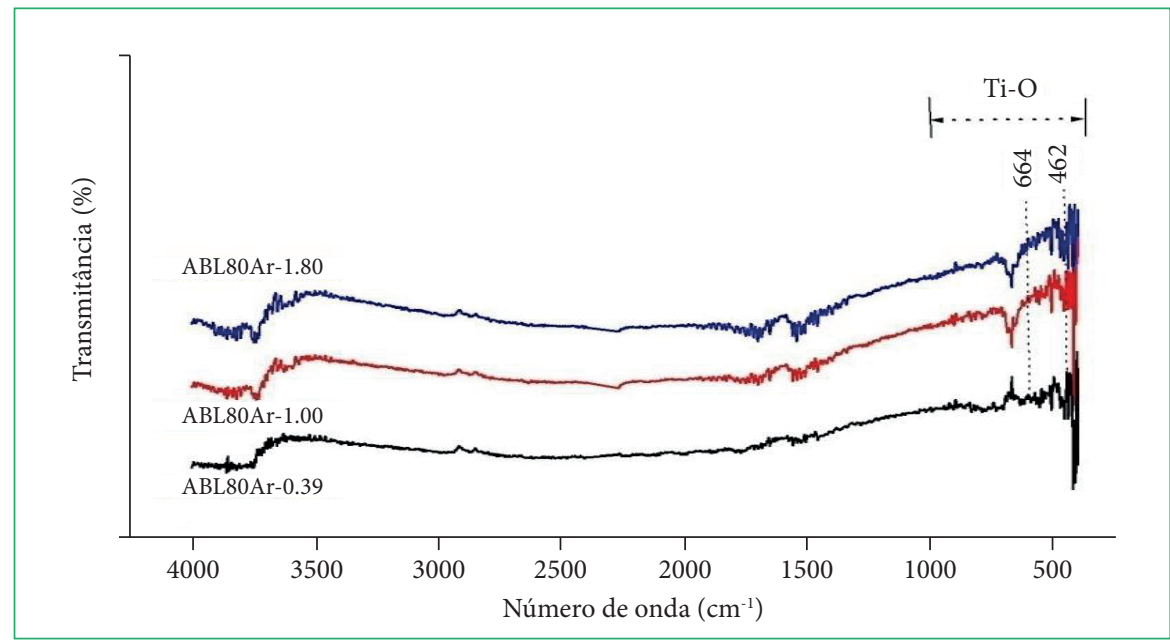

Figura 6: Espectros obtidos pela técnica de FTIR das superfícies com $80 \%$ de argônio e $20 \%$ de hidrogênio no processo de ablação a plasma.

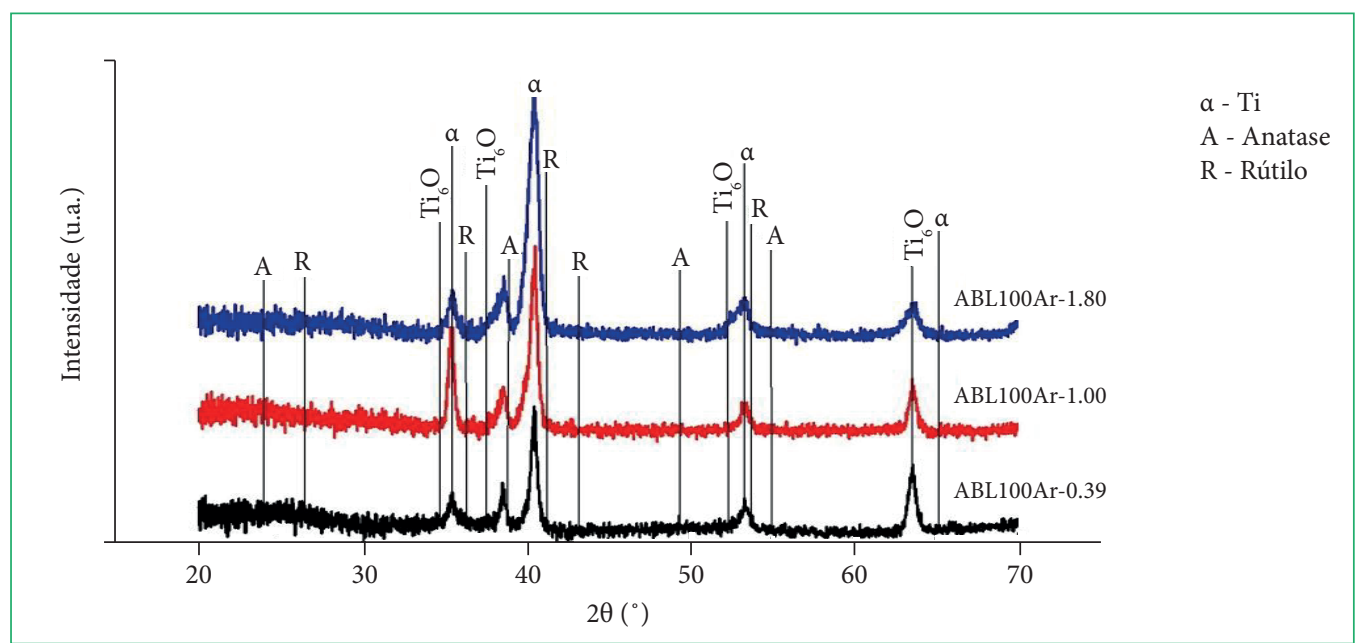

Figura 7: Difratogramas das superfícies limpas com 100\% de argônio no processo de ablação a plasma. 
presença de óxidos de titânio formados na superfície da amostra, evidenciando que esses parâmetros não foram efetivos na limpeza da amostra.

Esses resultados corroboram os resultados encontrados nos espectros de FTIR. São identificadas as fases anatase (TiO 2 ), rutilo $\left(\mathrm{TiO}_{2}\right), \mathrm{Ti}_{6} \mathrm{O}$ e $\mathrm{Ti}_{2} \mathrm{O}_{3}$ nas amostras tratadas somente com argônio. Como alguns picos de óxido são identificados nos ângulos similares aos picos relacionados ao da fase alfa ( $\alpha$ ), observa-se que os picos relacionados ao substrato são mais largos, devido à presença de mais de uma fase identificada nessas regiões. É observado também que, com o aumento da pressão, os picos relacionados aos óxidos apresentam intensidade menor, com picos relacionados à fase a mais intensos e estreitos, indicando diminuição dos picos relacionados aos óxidos nessas regiões.

Na Fig. 8 são apresentados os difratogramas referentes as amostras que foram tratadas com a adição de hidrogênio no processo de ablação a plasma, com uma mistura de $80 \%$ Ar e $20 \% \mathrm{H}_{2}$. Os picos referentes ao substrato de titânio da fase alfa ( $\alpha$ - hexagonal compacta) também são observados, presentes nos ângulos $35^{\circ}, 40^{\circ}, 55^{\circ}$ e $65^{\circ}$. As fases identificadas foram a anatase $\left(\mathrm{TiO}_{2}\right)$, rutilo $\left(\mathrm{TiO}_{2}\right), \mathrm{Ti}_{6} \mathrm{O}$ e $\mathrm{Ti}_{2} \mathrm{O}_{3}$. Esses picos estão associados aos picos referentes à fase $\alpha(\mathrm{Ti})$, apresentando picos mais largos, indicando presença de mais de uma fase nestas regiões. Para as superfícies que foram tratadas com $80 \% \mathrm{Ar}_{\text {e }} 20 \% \mathrm{H}_{2}$, a influência da pressão de trabalho também é verificada, observando que os picos referentes aos óxidos apresentam intensidade menor com o aumento da pressão e os picos relacionados ao material base ficam mais estreitos, devido à diminuição dos picos relacionados aos óxidos.

A técnica de EDS apresenta a concentração de oxigênio nas superfícies tratadas por ablação a plasma. Os resultados são apresentados na Fig. 9, em que a diminuição da concentração de oxigênio é observada, tanto com o aumento da pressão de trabalho quanto com a utilização da mistura de gás argônio e hidrogênio para a remoção do óxido no processo de limpeza, comprovando o que foi observado nas outras técnicas de caracterização realizadas.

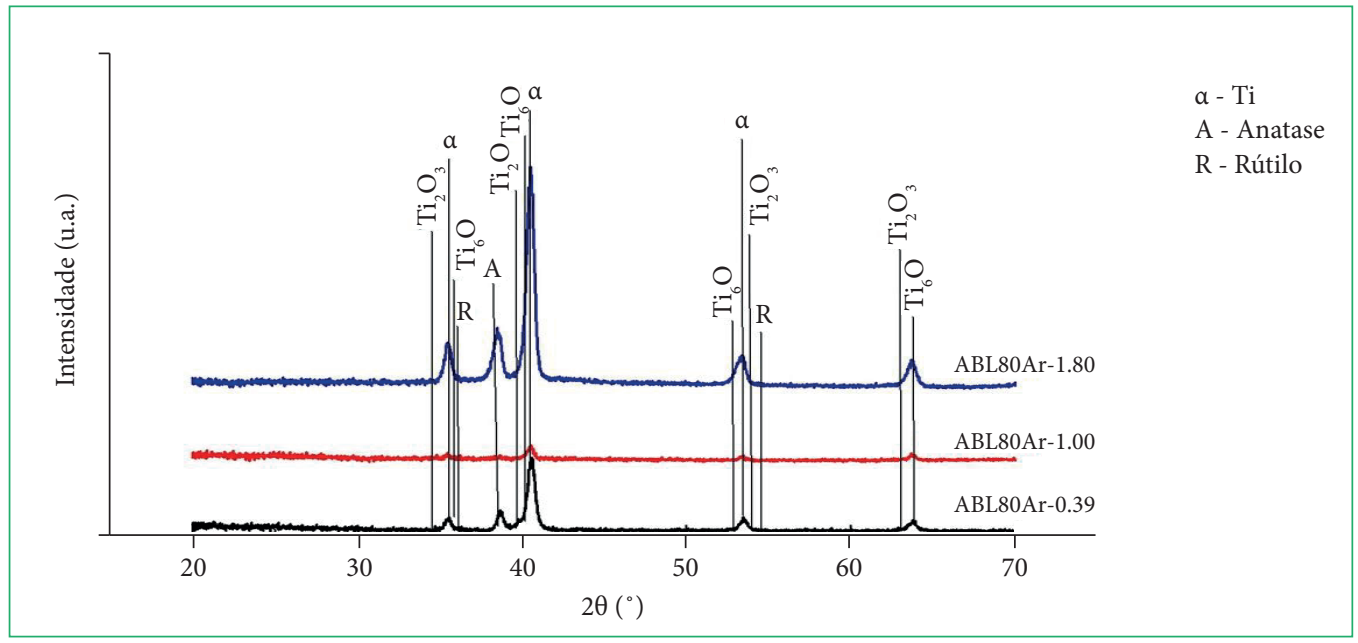

Figura 8: Difratogramas das superfícies tratadas com $80 \%$ de argônio e $20 \%$ de hidrogênio no processo de ablação a plasma.

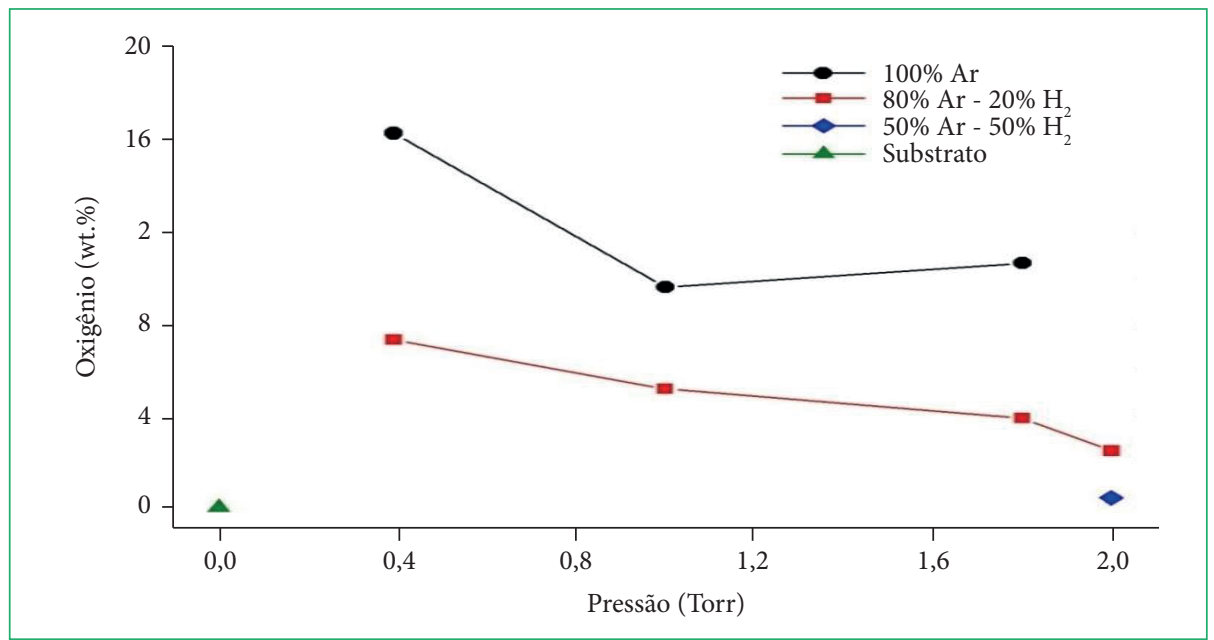

Figura 9: Variação da porcentagem de oxigênio obtido por EDS via MEV na superfície das amostras tratadas por ablação a plasma em função da pressão de tratamento. 
As amostras que apresentaram melhores condições de limpeza foram aquelas tratadas em pressões acima de 1,00 Torr. A amostra com $50 \%$ Ar e $50 \% \mathrm{H}_{2}(\mathrm{ABL} 50 \mathrm{Ar}-2.00)$ apresentou a menor proporção de oxigênio na superfície. Porém as amostras com mistura gasosa de $80 \%$ Ar e $20 \% \mathrm{H}_{2}(\mathrm{ABL} 80 \mathrm{Ar}-2.00)$, e com mistura gasosa de $80 \%$ Ar e $20 \% \mathrm{H}_{2}$ (ABL80Ar - 1.80) também apresentaram uma limpeza eficaz, cuja concentração de oxigênio na superfície da amostra estudada foi de 2,6 e 3,8\%, respectivamente. Os resultados comprovam a eficácia do hidrogênio para a limpeza do substrato.

O tratamento de limpeza por ablação a plasma realizado com argônio e hidrogênio propicia melhores resultados para a remoção de compostos orgânicos e inorgânicos, quando comparado à limpeza utilizando somente argônio. No tratamento de limpeza utilizando misturas de argônio e hidrogênio, o argônio remove os óxidos da superfície por bombardeamento iônico (sputtering) e aumenta a taxa de ionização, que favorece assim interações químicas entre os elementos presentes na superfície da amostra e também a combinação do hidrogênio com o oxigênio (etching), que é removido da câmara de tratamento através da renovação dos gases do reator ${ }^{13,25}$.

\section{Avaliação da influência do processo de ablação a plasma na adesão do filme DLC}

Os filmes DLC produzidos neste trabalho apresentaram coloração escura, como mostra a Fig. 10, com uniformidade do filme em toda a extensão da amostra.

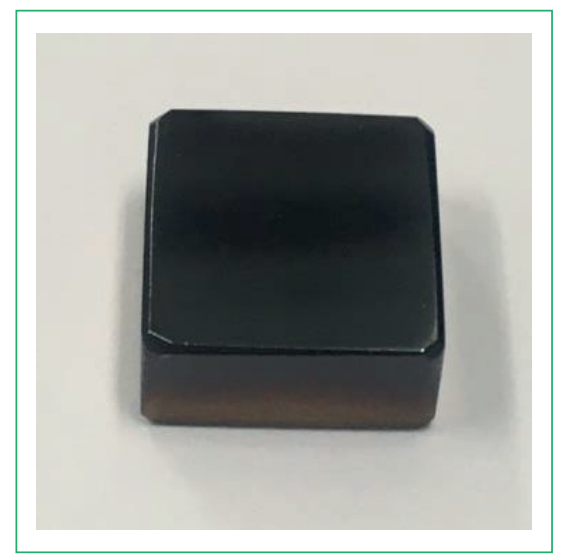

Figura 10: Aspecto visual da amostra após a deposição de filme DLC.

Os resultados da influência do processo de ablação a plasma na adesão dos filmes DLC depositados na liga estudada, avaliada pela técnica de dureza Rockwell C, são apresentados na Tabela 4.

Ao analisar a marca da indentação obtida após o teste de dureza sobre a superfície da amostra com o filme DLC depositado, é possível observar as regiões de destacamento do filme (regiões de coloração clara) e as regiões com presença de filme (coloração escura).

Ao avaliar as indentações, observou-se que o aumento da pressão na etapa da ablação a plasma aumenta a adesão do filme ao substrato, conforme observado nas amostras DLC-ABL100Ar - 1.80, DLC-ABL80Ar - 1.80 e DLC-ABL50Ar - 2.00. Entretanto para as amostras DLC-ABL100Ar - 0.39 e DLC-ABL100Ar - 1.80 a classificação é a mesma (HF6), correspondendo a uma baixa adesão do filme ao substrato. Com a adição de hidrogênio no processo de ablação, observou-se que o percentual de filme aderido à amostra ao redor da marca deixada pela indentação é superior, correspondendo a uma melhora na adesão do DLC ao substrato, conforme apresentado nas amostras DLC-ABL80Ar - 1.80 e DLC-ABL50Ar - 2.00 .

Os resultados de quantificação da área delaminada do filme são apresentados na Fig. 11. A quantificação das áreas delaminadas de filme DLC após a indentação para as amostras DLC-ABL100Ar - 0.39 e DLC-ABL100Ar - 1.80 classificadas como HF6 são distintas. A área delaminada na amostra DLC-ABL100Ar - 0.39 foi de 94,12\%, enquanto na amostra DLC-ABL100Ar - 1.80 foi de 57,95\%, mostrando a diferença entre eles mesmo com a mesma classificação qualitativa. É possível verificar com a análise quantitativa que a limpeza mais efetiva da superfície com o aumento da pressão no processo de ablação a plasma através da remoção dos óxidos aumenta a adesão do filme ao substrato.

As amostras DLC-ABL80Ar - 0.39 e DLC-ABL80Ar - 1.80 apresentaram área delaminada de 87,31 e 5,94\%, respectivamente. A adição de hidrogênio no processo de ablação evidencia a influência desse elemento na limpeza e, consequentemente, a adesão do filme ao substrato. O hidrogênio, juntamente com o argônio, promove remoção mais efetiva dos óxidos e das impurezas superficiais, influenciando positivamente na adesão do filme DLC à superfície metálica.

Com a quantificação da área delaminada é possível determinar que os melhores parâmetros de adesão do filme DLC ao substrato são obtidos para as amostras DLC-ABL80Ar - 1.80 e DLC-ABL50Ar - 2.00, que apresentam porcentagem de área delaminada de 5,94 e $6,96 \%$, respectivamente. 
Tabela 4: Análise da adesão do filme DLC depositado sob o substrato pelo ensaio de dureza Rockwell C.

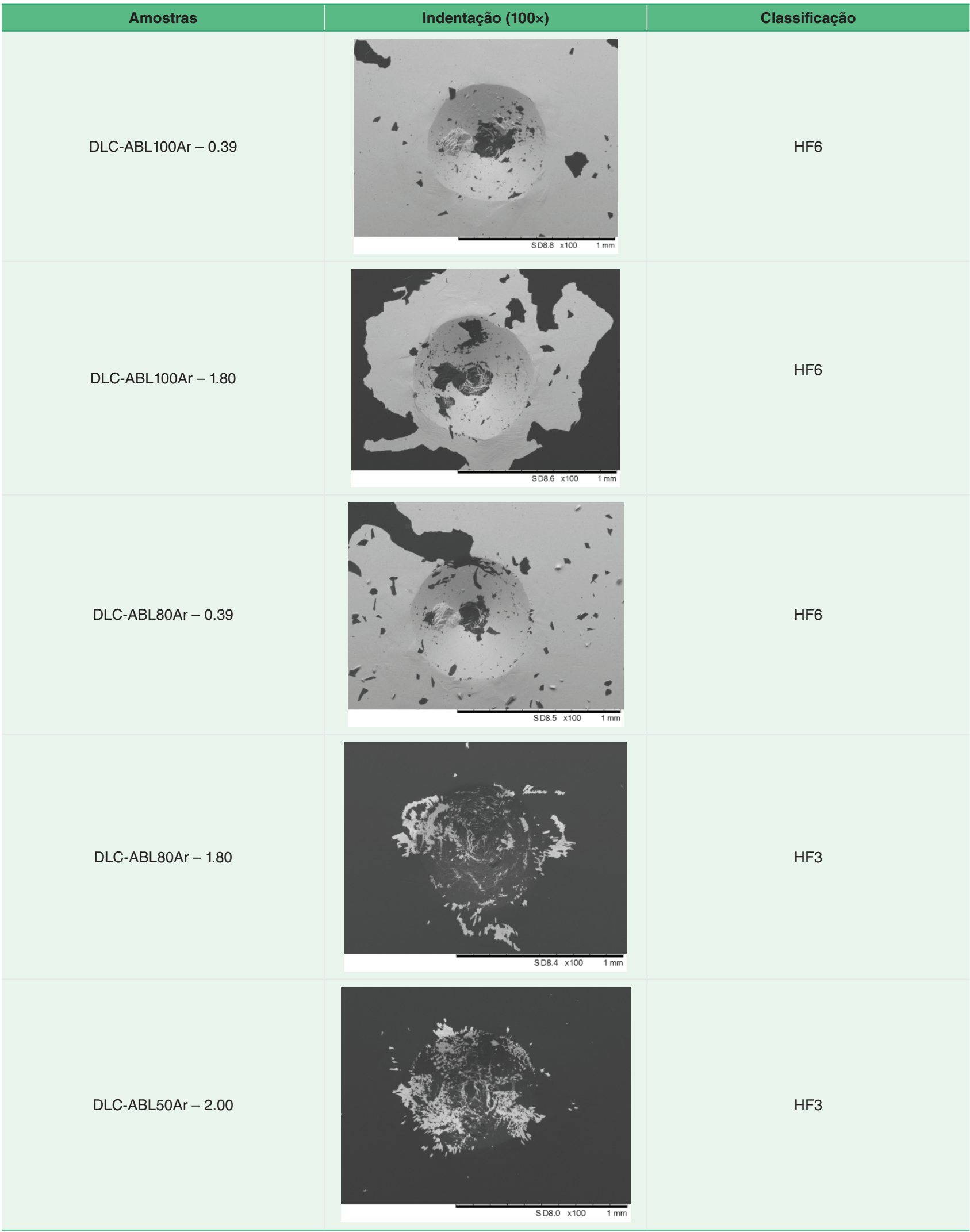

Assim, verifica-se que o tipo e porcentagem dos gases utilizados no processo de ablação, assim como a pressão de trabalho, agem na remoção de impurezas e óxidos da superfície metálica, influenciando de forma direta não só na adesão do filme DLC ao substrato, mas também na resistência ao desgaste deste, como ilustra a Fig. 12. 


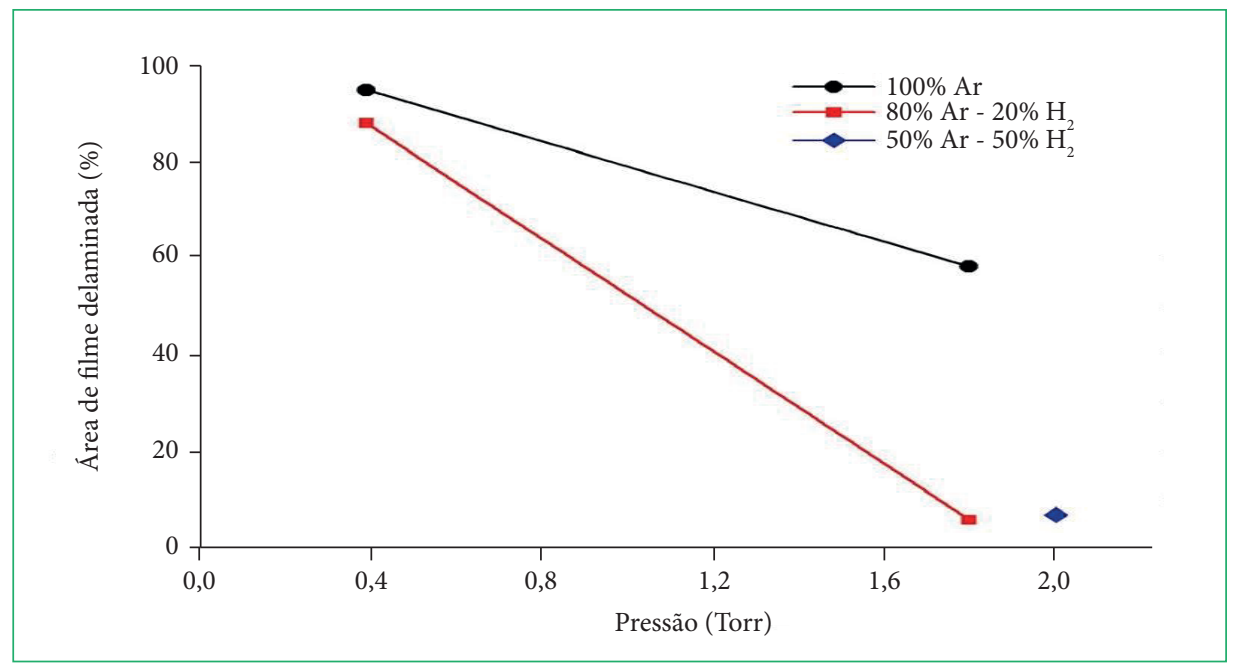

Figura 11: Porcentagem da área delaminada do filme após a indentação em função da pressão de trabalho do processo de ablação a plasma.

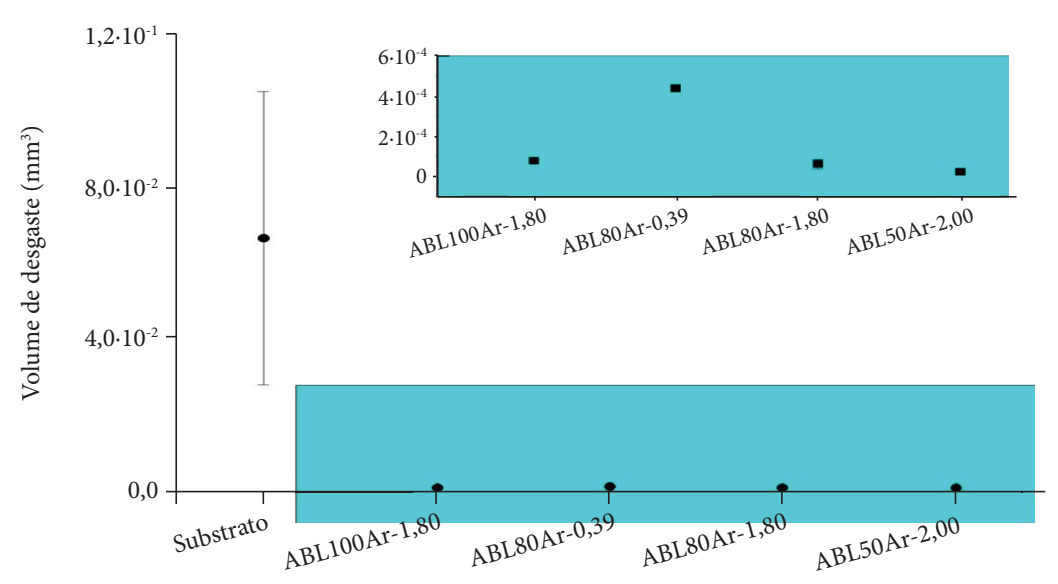

Na parte superior do gráfico principal é observado um retângulo de coloração azul que identifica as amostras cujos valores são apresentados no gráfico superior, com a redução da escala eixo y, para que a visualização da diferença entre as amostras seja destacada.

Figura 12: Volume de desgaste do filme DLC em função dos parâmetros de ablação a plasma.

A amostra DLC-ABL80Ar-0.39 foi a que apresentou maior volume de desgaste dentre todas estudadas. Observa-se que quanto maior pressão de trabalho, maior a remoção de óxidos e impurezas; consequentemente, o material apresenta maior resistência ao desgaste. As amostras com maior resistência ao desgaste foram aquelas que apresentaram maior adesão do filme ao substrato: DLC-ABL80Ar - 1.80 e DLC-ABL50Ar - 2.00 .

Assim, o ensaio de microdesgaste abrasivo evidenciou que o processo de ablação a plasma influencia a resistência ao desgaste do material com deposição de filme DLC. Com a remoção dos óxidos da superfície, as interações intermoleculares entre a intercamada de silício, o filme DLC e o substrato são mais efetivas, proporcionando um filme de maior adesão, o que diminui o desplacamento do filme durante o ensaio de desgaste, aumentando a resistência ao desgaste do material estudado.

\section{CONCLUSÃO}

Este estudo tornou possível determinar a melhor condição do processo de ablação a plasma para a limpeza da superfície da liga metálica $\mathrm{Ti}_{6} \mathrm{Al}_{4} \mathrm{~V}$, e, por consequência, a obtenção de um filme com melhor adesão ao substrato e melhor resistência ao desgaste.

As análises realizadas permitem concluir que as melhores condições de limpeza a plasma da amostra metálica apresentam ausência de colorações no material após o processo de ablação, com remoção dos óxidos presentes na superfície metálica. Essa condição é obtida em tratamentos com maiores pressões de trabalho e utilizando mistura de $\mathrm{Ar}$ e $\mathrm{H}_{2}$.

$\mathrm{O}$ estudo da adesão do filme DLC à superfície metálica da liga $\mathrm{Ti}_{6} \mathrm{Al}_{4} \mathrm{~V}$ apresentou resultados que corroboram o estudo do processo de ablação a plasma, podendo concluir que uma limpeza efetiva da superfície é um dos fatores determinantes para boa adesão do filme DLC ao substrato metálico. 
Os parâmetros dos processos de ablação que apresentaram maior influência na remoção de óxidos e impurezas superficiais foram a pressão de trabalho e a composição dos gases de tratamento, influenciando positivamente na adesão entre o filme e a superfície metálica, e, consequentemente, no aumento da resistência ao degaste do filme DLC depositado sobre a superfície da liga $\mathrm{Ti}_{6} \mathrm{Al}_{4} \mathrm{~V}$.

\section{FINANCIAMENTO}

Coordenação de Aperfeiçoamento de Pessoal de Nível Superior [https://doi.org/10.13039/501100002322]

Fundação de Amparo à Pesquisa do Estado de São Paulo [https://doi.org/10.13039/501100001807]

Processo 2017/12288-0; Processo 2016/13146-1

\section{REFERÊNCIAS}

1. Lopes BB. Artigo técnico - plasma: o agente promotor de adesão em polímeros e sua facilidade de inserção em processos produtivos. Plástico Moderno [Internet]. 2015. [citado em 15 Nov 2019]. Disponível em: https://www.plastico.com.br/artigo-tecnico-plasma-o-agentepromotor-de-adesao-em-polimeros-e-sua-facilidade-de-insercao-em-processos-produtivos/

2. Nogueira LC. Eficácia do uso de plasma em pressão atmosférica na adesão de cerâmicas zircônia [Tese]. [Belo Horizonte]: Faculdade de Odontologia, Universidade Federal de Minas Gerais; 2018.

3. Cruz D, Souza BA, Campos LAP, Almeida LS, Moreto JA, Manfrinato MD, et al. Projeto, construção e comissionamento de um reator para tratamento de nitretação iônica a plasma em aço P20. Rev Bras Apl Vac. 2018;37(3):102-13. https://doi.org/10.17563/rbav.v37i3.1107

4. Binder C, Bendo T, Hammes G, Klein AN, Mello JDB. Effect of nature of nitride phases on sliding wear of plasma nitrided sintered iron. Wear. 2015;332-333:995-1005. https://doi.org/10.1016/j.wear.2015.01.083

5. Grill A. Diamond-like carbon: state of the art. Diam Relat Mater. 1999;8(2-5):428-34. https://doi.org/10.1016/S0925-9635(98)00262-3

6. Dai M, Zhou K, Yuan Z, Ding Q, Fu Z. The cutting performance of diamond and DLC-coated cutting tools. Diam Relat Mater. 2000;9(910):1753-7. https://doi.org/10.1016/S0925-9635(00)00296-X

7. Cemin F, Bim LT, Menezes CM, Costa MEHM, Baumvol IJR, Alvarez F, CA Figueroa. The influence of different silicon adhesion interlayers on the tribological behavior of DLC thin films deposited on steel by EC-PECVD. Surf Coat Tech. 2015;283:115-21. https://doi.org/10.1016/j. surfcoat.2015.10.031

8. Robertson J. Diamond-like amorphous carbon. Mater Sci Eng R Rep. 2002;37(4-6):129-281. https://doi.org/10.1016/S0927-796X(02)00005-0

9. Petry ER. Efeito da temperatura na estrutura físico-química de intercamadas depositadas a partir de HMDSO para adesão de DLC em aço [Dissertação]. [Caxias do Sul]: Curso de Programa de Pós-Graduação em Materiais, Engenharia e Ciência dos Materiais, Universidade de Caxias do Sul; 2016

10. Barros RCM, Ribeiro MC, An-Sumodjo PT, Julião MSS, Serrano SHP, Ferreira NG. Filmes de diamante CVD dopado com boro. Parte I. Histórico, produção e caracterização. Quím Nova. 2005;28(2):317-25. https://doi.org/10.1590/S0100-40422005000200024

11. Franceschini DF, Freire Junior FL, Silva SRP. Influence of precursor gases on the structure of plasma deposited amorphous hydrogenated carbon-nitrogen films. Appl Phys Lett. 1996;68(19):2645-7. https://doi.org/10.1063/1.116268

12. Espindola ES. Influência da oxidação térmica sobre as propriedades da liga TI 6AL 4V para aplicações em próteses - tratamento térmico de 5 horas em ar ambiente. Rev E-Tech. 2012;Metalmecânica:92-104.

13. Silva MAM, Coutinho KD, Wanderley CDV, Guerra PVA. Limpeza a plasma para melhorar a adesão superficial de filmes de óxidos de titânio. R Bras Inov Tecnol Saúde. 2012;2(4):38-46. https://doi.org/10.18816/r-bits.v2i4.3392

14. 14. Peng XL, Clyne TW. Mechanical stability of DLC films on metallic substrates Part II — Interfacial toughness, debonding and blistering Thin Solid Films. 1998;312(1-2):219-27. https://doi.org/10.1016/S0040-6090(97)00703-7

15. Jones BJ, Anguilano L, Ojeda JJ. Argon plasma treatment techniques on steel and effects on diamond-like carbon structure and delamination. Diam Relat Mater. 2011;20(7):1030-5. https://doi.org/10.1016/j.diamond.2011.06.004

16. Vidakis N, Antoniadis A, Bilalis N. The VDI 3198 indentation test evaluation of a reliable qualitative control for layered compounds. J Mater Process Technol. 2003;143-144:481-5. https://doi.org/10.1016/S0924-0136(03)00300-5

17. Capote G, Bonetti LF, Santos LV, Trava-Airoldi VJ, Corat EJ. Adherent amorphous hydrogenated carbon films on metals deposited by plasma enhanced chemical vapor deposition. Thin Solid Films. 2008;516(12):4011-7. https://doi.org/10.1016/j.tsf.2007.08.007

18. Cozza RC, Tanaka DK, Souza RM. Friction coefficient and abrasive wear modes in ball-cratering tests conducted at constant normal force and constant pressure - preliminary results. Wear. 2009;267(1-4):61-70. https://doi.org/10.1016/j.wear.2009.01.055

19. Collison WZ, Ni TQ, Barnes MS. Studies of the low-pressure inductively-coupled plasma etching for a larger area wafer using plasma modeling and Langmuir probe. J Vac Sci Technol. 1998;16(1):100-7. https://doi.org/10.1116/1.580955 
20. Chapman B. Glow discharge processes: sputtering and plasma etching. New York: John Wiley \& Sons; 1980.

21. Siqueira RC. Estudo da influência da oxidação a plasma nas propriedades tribológicas da liga metálica Ti-6Al-4V [Dissertação]. [Sorocaba]: Universidade Federal de São Carlos; 2019.

22. Pavia DL, Lampman GM, Kriz GS, Vyvyan JR. Introdução à espectroscopia: Tradução da $4^{a}$ edição norte-americana. São Paulo: Cengage Learning; 2010

23. Zhang J-Y, Boyd IW, O'Sullivan BJ, Hurley PK, Kelly PV, Sénateur J-P. Nanocrystalline TiO2 films studied by optical, XRD and FTIR spectroscopy. J Non-Cryst Solids. 2002;303(1):134-8. https://doi.org/10.1016/S0022-3093(02)00973-0

24. Petasch W, Kegel B, Schmid H, Lendenmann K, Keller HU. Low-pressure plasma cleaning: a process for precision cleaning applications Surf Coat Tech. 1997;97(1-3):176-81. https://doi.org/10.1016/S0257-8972(97)00143-6

25. Hsieh JH, Li C. Effects of hollow cathode and Ar/H2 ratio on plasma cleaning of Cu leadframe. Thin Solid Films. 2006;54(1-2):101-3. https:// doi.org/10.1016/j.tsf.2005.09.050 